The method of Rupp and Schied', depending upon the oxidation of the sulphocyanate by free iodine in bicarbonate solution and titration of the unused iodine, was shown by Thiele ${ }^{2}$ to be inaccurate, owing to the incomplete oxidation of the sulphocyanate in the half-hour's time proposed by Rupp and Schied. Thiele states that if the oxidation be continued for four hours the results are accurate; in this modified form Rupp has adopted the method, and claims good results from its use. In view however of Stokes' results on the decomposition of sulphocyanates and Treadwell's statement that complete oxidation to sulphuric acid requires the most vigorous treatment with fuming nitric acid, it may be doubted whether the oxidation by iodine follows quantitatively the simple equation expressed.

NEW YORK UNIVERSITY,

July, 1907.

\title{
THE USE OF SODIUM CARBONATE AND ZINC OXIDE IN SULPEUR AND ARSENIC DETERMINATIONS.
}

By W. C. ERATGH AND C. B. SPRAgUE. Received July $I 7$, I907.

A method involving the use of sodium carbonate and zinc oxide for sulphur and arsenic determinations was devised by one of $1 \mathrm{~s}^{4}$ some years ago, and has given uniform satisfaction in various assay offices for so long a time that an account of it should be made public.

One part of dry sodium carbonate and four parts of zinc oxide are mixed thoroughly. In the case of sulphur determinations a weighed sample of the material to be analyzed, usually one half gram, is mixed intimately with enough of the sodium carbonate-zinc oxide reagent to afford at least twice as much sodium carbonate as would be required by the sulphur, atsenic, etc., present, placed in a small porcelain dish, covered with the reagent and heated to redness in a muffle for fifteen or twenty min. utes. A shorter period of heating is usually sufficient, but the time here specified is ample for all cases. The residue is then extracted with water, boiled, filtered, the filtrate made acid with hydrochloric acid, precipitated with barium chloride, and the barium sulphate treated as usual.

In an arsenic determination the substance is treated as above unti 1 the alkaline solution is filtered from the residue. This filtrate is acidified with acetic acid, precipitated with silver nitrate, boiled for a few minutes and then filtered. The precipitate of silver arsenate is washed thoroughly with hot water and then dissolved in dilute nitric acid, its silver conter: being determined finally by titration with ammonium or potassium sul-

I Ber, 35, 2191 ( I902).

2 Ber., 35, 2766 (1902).

${ }^{3}$ Arch. Pharm., 243, 468 (1905): This Journal, 28, I771 (1906); J. Chem. Soc. (Abstracts) 88, 867 (I 905 ).

${ }^{4}$ C. B. S. 
phocyanate in the usual way. Ferric sulphate is used as an indicator. In calculating the arsenic present use the proportion :

$3 \mathrm{Ag}:$ I As : : Weight of silver found: Weight of arsenic present.

The method has been tried successfully with various sulphides such as galenite, pyrite, arsenopyrite, chalcopyrite, sphalerite, etc.; with sulphates like gypsum and anglesite; and with metallurgical products like matte, speiss and flue dust. In the case of analyses of heavyspar the method is not superior to the ordinary fusion with an alkali. The fact that the decomposition with sodium carbonate and zinc oxide has been employed for control and umpire assays upon ores in commercial work for so long a period without objection, is evidence that the results obtained by the method are accurate.

It will be seen that the method for sulphur is a modification of the well known Eschka method, and that for arsenic, is an improvement upon Pearce's method. The advantages of the decomposition described are: (1) that the mass resulting from the heating is not fused, but can be removed readily from the dish and leached with water; (2) the ease and speed with which sulphides, sulphates, arsenates, etc., are decomposed; (3) no time-consuming subsequent evaporations are necessary; and (4) the absence of a large quantity of alkaline and other salts from the solutions in which the precipitatious of barium sulphate and silver arsenate are effected. UNIVERSTTY OF LTAH, June 5 th, I907.

\section{THE QUANTITATIVE DETERMINATION OF CARBON BISULPHIDE IN A MIXTURE OF BENZENE AND CARBON BISULPHIDE.}

BY EVERHART PERCY HARDING AND JAMES DORAN.

Received August 5 , jon7.

This paper is a preliminary paper to one entitled " The Technical Determination of Carbon Bisulphide in Illuminating Gas," in which determination the carbon bisulphide was separated in the form of potassium xanthate and the carbon bisulphide in the xanthate volumetrically determined by titrating with a standard solution of cupric acetate. In order to calculate the percentage of carbon bisulphide, it is necessary to know the ratio of the copper or cupric oxide to the carbon bisulphide in the copper xanthate formed.

According to the most generally accepted formula of the xanthate formed, it is a cuprous compound with the formula (CS.OC $\left.\mathrm{H}_{3} \mathrm{~S}\right)_{2} \mathrm{Cu}_{2}$ in which the ratio of the $\mathrm{CuO}_{\mathrm{O}} \mathrm{CS}_{2}$ is $\mathrm{r}, 0: 0.956 \mathrm{r}$. But Edward S. John$\operatorname{son}^{1}$ found the ratio gravimetrically determined, to vary from I.0:I.593 to I.O:I.825, depending upon conditions under which the determination was made. Macagno ${ }^{2}$ by a volumetric method found the ratio of $\mathrm{CuO}$ to $\mathrm{CS}_{\text {. }}$ to be 1.0:1.93 I. Others have found a ratio varying not much from that

'This Journal, 28, 1209 .

${ }^{2}$ Chem. News, 43, 148 . 